\title{
Urticária multiforme: a propósito de um caso clínico
}

Diana Reis Monteiro, ${ }^{1}$ Sofia Fernandes ${ }^{1}$

\section{RESUMO}

Introdução: O exantema em idade pediátrica representa frequentemente um desafio na prática clínica diária, na medida em que pode estar enquadrado numa grande variedade de patologias, com atingimento cutâneo isolado ou sistémico, incluindo patologias benignas e autolimitadas e situações de maior gravidade que podem requerer uma atitude mais interventiva. Os autores relatam um caso de urticária multiforme, com o objetivo de recordar os aspetos semiológicos característicos desta patologia, o seu caráter benigno, os diagnósticos diferenciais a considerar e a terapêutica a instituir.

Descrição do caso: Lactente de onze meses, do sexo masculino, sem antecedentes patológicos de relevo, trazido ao serviço de urgência por exantema evanescente e edema periférico com cerca de 24 horas de evolução, sem febre ou outras queixas associadas. Tinha terminado amoxicilina com ácido clavulânico por otite média aguda dois dias antes da vinda. Ao exame físico destacava-se um exantema maculopapular, com lesões anulares, policíclicas, de halo eritematoso e centro claro, disperso pela face, tronco e membros, pruriginoso, associado a edema ligeiro das mãos, pés e face, sem petéquias, sem atingimento das mucosas nem outras alterações relevantes. Não se considerou necessária a realização de exames complementares, tendo tido alta com diagnóstico de urticária multiforme em contexto pós-infecioso/pós-farmacológico, medicado com anti-histamínico e corticoide por via oral. Verificou-se resolução completa das lesões cerca de 48 horas depois.

Comentário: A urticária multiforme é uma patologia benigna e autolimitada que surge sobretudo em idade pediátrica, caracterizada pelo aparecimento de exantema maculopapular eritematoso, com lesões anulares e policíclicas, evanescente, facilmente confundível com outras patologias mais graves. Inicialmente pode assemelhar-se a eritema multiforme, doença do soro-like, vasculite urticariforme e edema hemorrágico da infância; no entanto, estas entidades representam patologias distintas, com abordagens e prognósticos diferentes, sendo extremamente importante a distinção clínica entre as mesmas.

Palavras-chave: Exantema; Urticária; Lactente.

\section{INTRODUÇÃO}

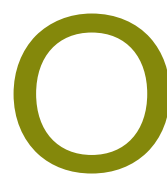

exantema em idade pediátrica representa frequentemente um desafio na prática clínica diária, na medida em que pode estar enquadrado numa grande variedade de patologias, com atingimento cutâneo isolado ou sistémico, incluindo patologias benignas e autolimitadas e situações de maior gravidade que podem requerer uma atitude mais interventiva.

Perante uma criança com exantema deve ser feita uma análise pormenorizada das lesões, com o objetivo de as caracterizar relativamente ao tipo de lesão (como mácula, pápula, placa, nódulo, vesícula, bolha, pústula, entre outras), à configuração da lesão (linear, anular, numular, em alvo, reticulada, entre outras), à sua

1. Centro Hospitalar de Entre Douro e Vouga, Santa Maria da Feira, Portugal. textura, localização e distribuição. Esta análise, juntamente com uma anamnese completa, será essencial para orientar o raciocínio clínico e a abordagem ao doente.

A urticária multiforme é uma patologia benigna e autolimitada, que surge sobretudo na idade pediátrica, caracterizada pelo aparecimento de um exantema maculopapular eritematoso evanescente, com lesões anulares e policíclicas, facilmente confundível com outras patologias mais graves. Uma história clínica detalhada e um exame físico pormenorizado permitem na maioria das vezes estabelecer o diagnóstico diferencial e direcionar a abordagem do doente, de forma a reconhecer situações que requerem investigação adicional e terapêutica específica.

Os autores relatam um caso de urticária multiforme num lactente de onze meses, com o objetivo de 


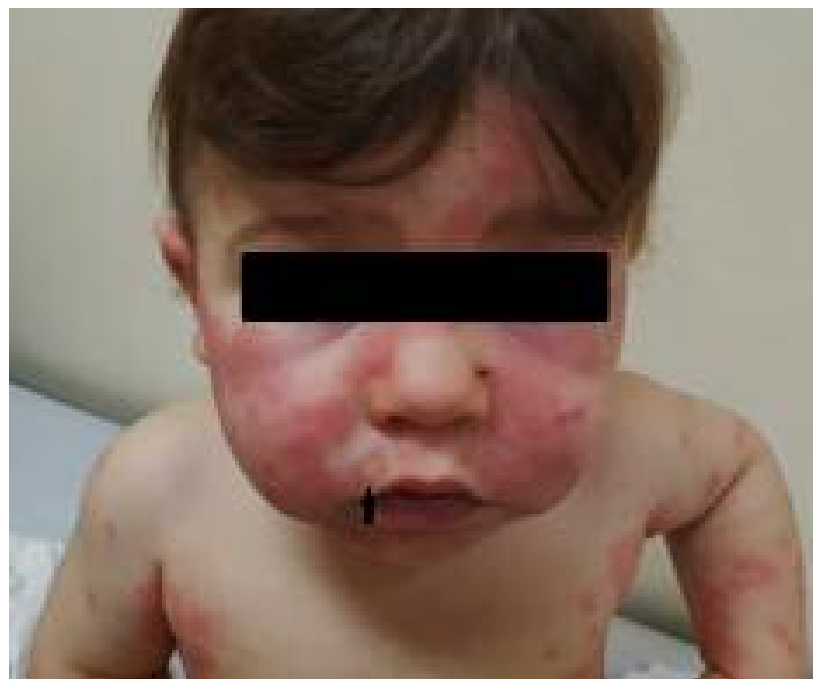

Figura 1. Exantema maculopapular, com lesões anulares, policíclicas (assinalado exemplo), associado a discreto edema da face.

recordar os aspetos semiológicos característicos desta patologia, o seu caráter benigno, os diagnósticos diferenciais a considerar e a terapêutica a instituir.

\section{DESCRIÇÃO DO CASO}

Lactente de onze meses, sexo masculino, caucasiano. Segundo filho de casal não consanguíneo, inserido numa família nuclear, classe IV de Graffar, estadio III do ciclo de vida de Duvall. Sem antecedentes patológicos de relevo nem alergias medicamentosas conhecidas, com o programa nacional de vacinação atualizado, foi trazido ao serviço de urgência por exantema e edema periférico com cerca de 24 horas de evolução. Não apresentava febre, sintomas respiratórios, gastrointestinais, genitourinários, artralgias ou outras queixas associadas. Tinha terminado ciclo de amoxicilina com ácido clavulânico por otite média aguda dois dias antes da vinda.

Ao exame físico destacava-se exantema maculopapular, com lesões anulares, policíclicas, de halo eritematoso e centro claro, disperso pela face, tronco e membros, pruriginoso, associado a edema ligeiro das mãos, pés e face, sem petéquias (Figuras 1 a 4). Relativamente ao restante exame, estava apirético, apresentava bom estado geral, mucosas coradas e hidratadas, sem enantema, boa perfusão periférica, sinais meníngeos negativos, auscultação cardiopulmonar sem alte-

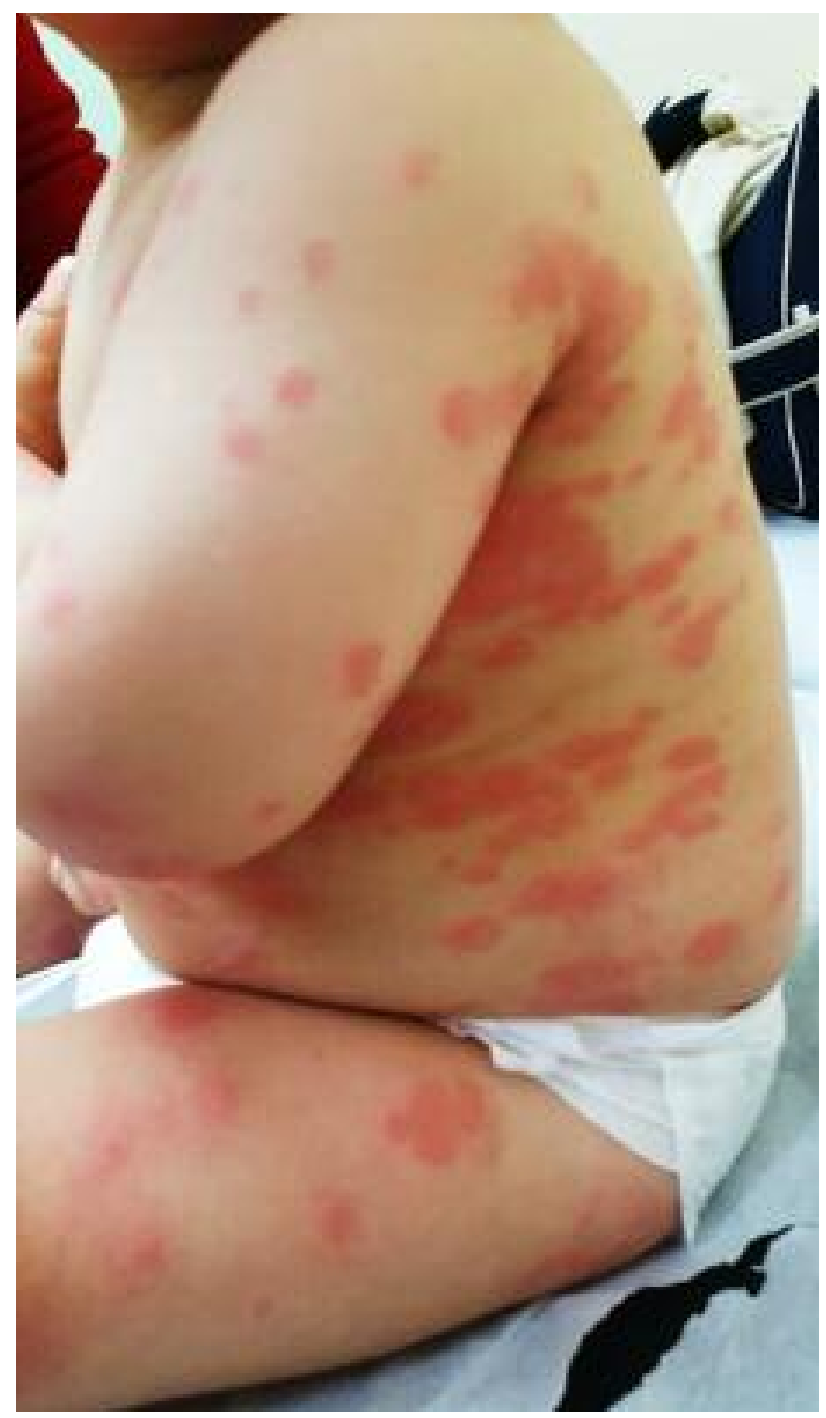

Figura 2. Exantema maculopapular, com lesões anulares, policíclicas, no tronco.

rações, sem sinais de dificuldade respiratória, abdómen indolor a palpação, sem massas ou organomegalias palpáveis, otoscopia e inspeção da orofaringe sem alterações.

Perante o quadro não se considerou necessária a realização de exames complementares e o doente teve alta com diagnóstico de urticária multiforme em contexto pós-infecioso/pós-farmacológico, medicado com anti-histamínico e corticoide por via oral.

Foi explicado o quadro clínico aos pais, tranquilizando-os, mas ressalvando que seria recomendável 


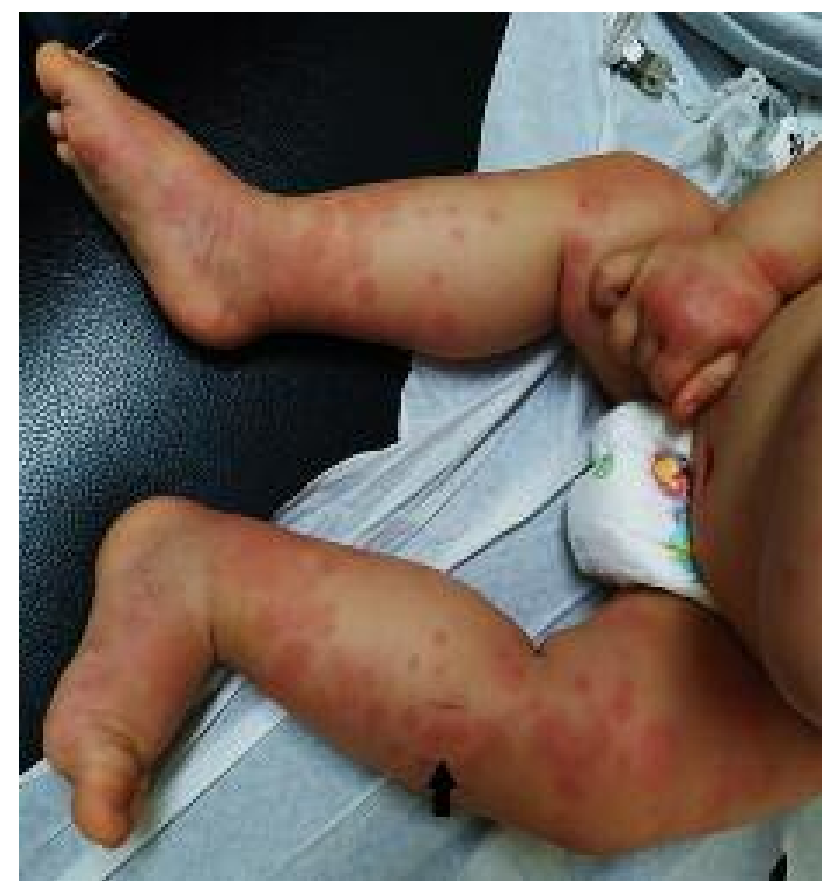

Figura 3. Exantema maculopapular e em placa, com lesões anulares, policíclicas, algumas semelhantes a lesões em alvo (assinalada), associado a edema dos pés e mãos.

uma reavaliação a curto prazo para constatar a melhoria das lesões e pelo facto de esta entidade poder assemelhar-se, numa fase inicial, a outras patologias mais graves.

Verificou-se resolução completa das lesões cerca de 48 horas depois.

\section{COMENTÁRIO}

A urticária multiforme, também conhecida como urticária anular aguda, trata-se de uma reação de hipersensibilidade cutânea benigna, que se caracteriza pelo aparecimento de lesões maculares, papulares e em placa, anulares, policíclicas, em alvo, com halo eritematoso e centro claro, localizadas no tronco, face e extremidades, associadas a edema acral (sem laringoedema), prurido e dermatografismo. ${ }^{1-7}$ Associa-se a bom estado geral e ocasionalmente a febre baixa-moderada de curta duração. ${ }^{1,3-4,6}$ Distingue-se de outras patologias com lesões cutâneas semelhantes, na medida em que as lesões são tipicamente evanescentes, ${ }^{1-5}$ cada qual com duração inferior a 24 horas $^{1-4}$ e não apresenta artralgias nem envolvimento das mucosas. ${ }^{1,3}$

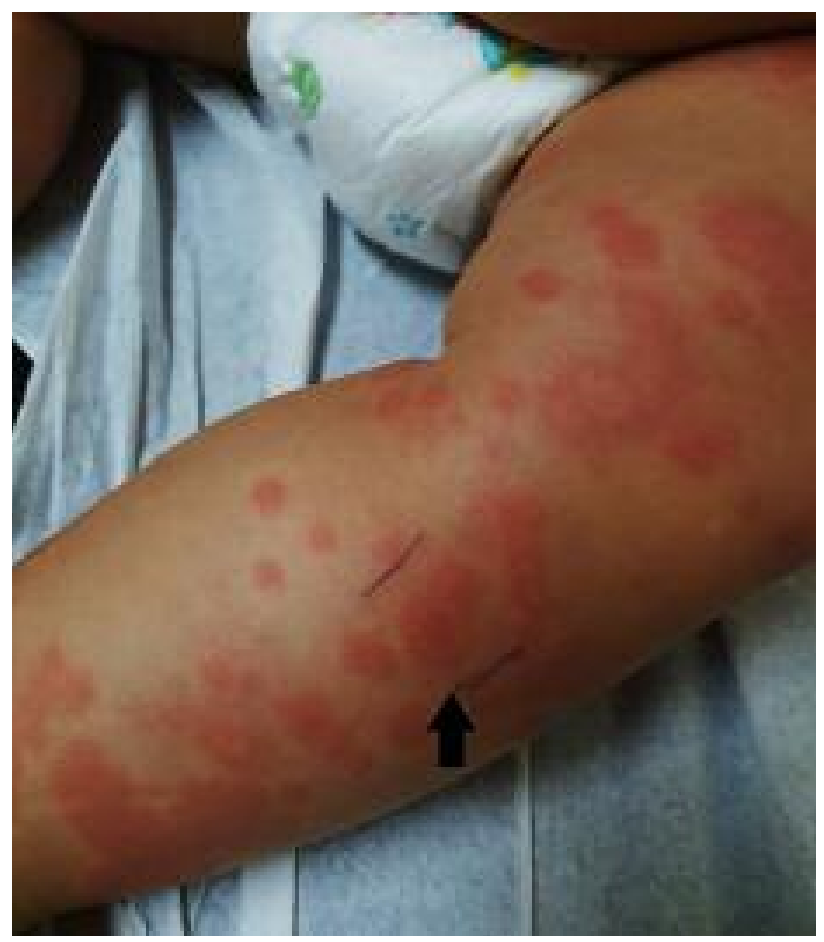

Figura 4. Lesão que se parece com uma lesão em alvo, mas que se distingue desta última por não possuir um centro verdadeiramente equimótico/purpúrico, que depois evolui para necrose central.

Trata-se de uma patologia específica de idade pediátrica, sendo que afeta sobretudo crianças dos quatro meses aos quatro anos. ${ }^{1-2,4,6}$ É autolimitada, com resolução total do quadro habitualmente em menos de duas semanas. ${ }^{1-2,4-6}$ Pode estar relacionada com história de infeção prévia (nomeadamente infeção das vias aéreas superiores, otite ou outra infeção viral), quadro infecioso concomitante com o aparecimento das lesões, bem como imunizações recentes ou fármacos (nomeadamente amoxicilina, aspirina, cefalosporinas e macrólidos)..$^{1-6}$

Os exames complementares não são essenciais para estabelecer o diagnóstico já que não revelam achados específicos. ${ }^{1,4,6}$ Preconiza-se tratamento apenas de suporte, com a descontinuação de fármacos que não sejam essenciais, toma de anti-histamínicos para controlo sintomático e, apesar de não ser consensual, pode estar indicado tratamento com corticoides em casos mais graves refratários aos anti-histamínicos. ${ }^{1-6}$ No caso descrito optou-se pelo tratamento com corticoide desde uma fase inicial pela exuberância das lesões. 
A abordagem de um doente pediátrico com lesões anulares deve iniciar-se com uma anamnese completa, questionando especificamente sobre a apresentação das lesões, tempo de evolução, sintomas sistémicos associados, antecedentes familiares, consumo de fármacos e intercorrência infeciosa recente. ${ }^{1,3}$ Esta informação, juntamente com um exame físico pormenorizado, permite na maioria das vezes estabelecer o diagnóstico diferencial e direcionar a abordagem do doente, de forma a reconhecer situações que requerem investigação adicional e terapêutica específica. ${ }^{1,3}$

Relativamente ao diagnóstico diferencial, esta entidade é frequentemente confundida com eritema multiforme, doença do soro-like, vasculite urticariforme e edema hemorrágico da infância. No entanto, estas entidades representam patologias distintas, com abordagens e prognósticos diferentes, sendo extremamente importante a distinção clínica entre as mesmas. ${ }^{1-6}$

O eritema multiforme é uma reação imunomediada que pode afetar doentes de todas as idades e consiste no aparecimento de lesões em alvo clássicas, com centro violáceo que pode transformar-se em bolha e evoluir para lesão necrótica, na face, extremidades superiores e inferiores, nomeadamente dorso das mãos, palmas e plantas, bem como região perineal..$^{1-5,7-8}$ As lesões são fixas, podem durar desde dias a semanas e existe normalmente atingimento de mucosas. ${ }^{1,4,7-8} \mathrm{O}$ edema associado é raro, não há dermatografismo e normalmente não há prurido, sendo referida sensação de queimadura. ${ }^{1,4} \mathrm{~A}$ associação com infeção tem sido mencionada como principal agente causador, sobretudo por herpes simplex vírus e Mycoplasma pneumoniae, embora se identifiquem outros agentes infeciosos com menor frequência, bem como alguns fármacos. ${ }^{1,4,7-8}$ Analiticamente não existem achados específicos, ${ }^{8}$ estando descritos casos de aumento dos parâmetros inflamatórios ${ }^{1,7}$ e hepáticos. ${ }^{1} \mathrm{O}$ diagnóstico baseia-se na anamnese e exame físico, sendo que a biópsia pode ser útil para confirmação em casos de dúvida. ${ }^{8}$ Relativamente ao tratamento, não é consensual a sua utilização; no entanto, pode ponderar-se iniciar terapêutica com corticoide por via oral e em caso de infeção por herpes simplex o valaciclovir ou famciclovir via oral podem ser considerados. . $^{1,4}$,

A doença do soro-likeé uma reação imune que pode ter uma apresentação clínica variável, com exantema maculopapular ou em placa, com lesões urticariformes, policíclicas, com centro claro ou por vezes descritas como tendo aspeto equimótico ${ }^{1,3-4,9} \mathrm{e}$ artrite ou artralgia. ${ }^{3,9}$ As lesões distribuem-se pela face, tronco, extremidades e margem lateral das mãos e pés. ${ }^{1,3-4}$ Pode também estar presente febre alta, mialgias e adenomegalias. ${ }^{1,3-4,9}$ As lesões cutâneas são fixas e podem durar desde dias a semanas, ${ }^{1-4,9}$ podendo apresentar hiperpigmentação residual posteriormente. ${ }^{9}$ Assim como na urticária multiforme pode existir edema acral, nesta entidade o mais característico é o atingimento articular incapacitante, sendo as articulações das mãos e dos pés mais frequentemente envolvidas. ${ }^{9}$ Distingue-se do eritema multiforme por não apresentar envolvimento das mucosas..$^{1,49} \mathrm{Tem}$ sido associada à toma de antibióticos, particularmente beta-lactâmicos, mas outros fármacos têm sido igualmente apontados como trigger, ${ }^{1,3-4,9}$ sendo que a exposição pode ter ocorrido dias ou semanas antes e pode não haver antecedentes de reação em tomas prévias do mesmo fármaco. ${ }^{4,9} \mathrm{O}$ diagnóstico deve ser primariamente feito com base na história clínica e exame objetivo, uma vez que os exames complementares não mostram alterações específicas, tendo sido reportados casos com aumento de parâmetros inflamatórios, ${ }^{9}$ neutropenia, linfocitose, bem como trombocitopenia e eosionofilia. ${ }^{1}$ Preconiza-se a descontinuação de antibióticos e fármacos de início recente, bem como tratamento de suporte com anti-histamínicos e anti-inflamatórios não esteroides para controlo do prurido e artralgia, reservando os corticoides para casos com apresentação mais grave. ${ }^{1,49}$ Associa-se a bom prognóstico, embora estejam descritos casos cuja resolução tardou várias semanas. ${ }^{9}$

A vasculite urticariforme, por sua vez, afeta maioritariamente doentes em idade adulta, embora haja casos reportados em doentes pediátricos. ${ }^{1,3}$ Consiste em lesões de urticária e evidência de vasculite na biópsia de pele. ${ }^{1,3,10}$ Manifesta-se por lesões urticariformes com centros purpúricos, na face, tronco, extremidades e margem lateral de mãos e pés, podendo apresentar também atingimento extracutâneo, nomeadamente articular, pulmonar, renal e gastrointestinal. ${ }^{1,3,10}$ As manifestações sistémicas mais comuns são artralgias e artrite. ${ }^{10}$ As lesões cutâneas são fixas e têm duração de dias a semanas. ${ }^{1,3,10}$ Existe habitualmente envolvimento das mucosas com lesões da cavidade oral e por vezes 
conjuntiva, mucosa nasal e urogenital, bem como angioedema e/ou edema acral. ${ }^{1}$ Pode haver referência a prurido, por vezes associado a sensação de queimadura e/ou dor. ${ }^{3,10}$ Pode surgir no contexto de infeções, doenças autoimunes, neoplasias e toma de fárma$\cos ^{1,3,10}$ Analiticamente pode manifestar-se com aumento da velocidade de sedimentação, hipocomplementemia, anticorpos antinucleares positivos, micro-hematuria e proteinuria. ${ }^{1,10}$ É reconhecida como uma doença benigna e autolimitada na maioria dos casos, particularmente aqueles com níveis normais de complemento, embora os sintomas possam durar anos em alguns doentes. ${ }^{710}$ Quando associada a hipocomplementemia tem pior prognóstico, estando associada a doença sistémica mais grave. ${ }^{10} \mathrm{Em}$ termos de tratamento, os corticoides sistémicos são considerados a base da terapêutica, podendo associar-se a anti-histamínicos para controlo do prurido, bem como anti-inflamatórios não-esteroides para as artralgias. ${ }^{1,10} \mathrm{Em}$ caso de doença moderada-grave são usados os corticoides em combinação com dapsona, colchicina ou hidroxicloroquina. ${ }^{10}$

O edema hemorrágico agudo da infância é uma vasculite de pequenos vasos caracterizada por exantema urticariforme, que evolui para placas purpúricas em alvo, distribuído sobretudo na face, pavilhões auriculares, genitais e extremidades, associado a febre e edema acral. ${ }^{3,11-12}$ Envolvimento de outros sistemas além da pele é raro, embora estejam descritos casos raros graves de envolvimento renal, gastrointestinal e articular. ${ }^{11}$ Afeta geralmente crianças menores de dois anos., ${ }^{311-12}$ Pode ser despoletado por quadro infecioso prévio (nomeadamente otite média aguda, infeção urinária, infeção das vias respiratórias superiores e pneumonia), ingestão de fármacos ou imunizações. ${ }^{11-12} \mathrm{Em}$ termos analíticos os achados são inespecíficos, podendo haver trombocitose, leucocitose com eosionofilia ou linfocitose, aumento da proteína $\mathrm{C}$ reativa e velocidade de sedimentação ${ }^{11-12}$ e, em alguns casos, hipocomplementemia e alteração da função hepática. ${ }^{11} \mathrm{O}$ diagnóstico é clínico mas, em caso de dúvida, a biópsia pode ser útil. ${ }^{11-12}$ É uma doença geralmente benigna e autolimitada, que requer apenas tratamento de suporte na maioria das situações. ${ }^{11-12}$ Em casos mais graves ou com envolvimento extracutâneo persistente pode estar indicado tratamento com corticoides. ${ }^{11}$
Além das patologias referidas previamente existem outras entidades a considerar no diagnóstico diferencial face a um exantema com lesões anulares, a saber:

- A Tinea corporis é uma infeção fúngica, que causa lesão isolada ou várias lesões de tamanhos distintos, com margem eritematosa e centro mais claro, que evolui de forma centrífuga. ${ }^{2-3}$

- A pitiríase rósea trata-se de uma doença autolimitada, precedida por sintomas respiratórios superiores, com várias lesões em placa, ovaladas, com eritema central e margens mais claras e descamativas, localizadas no tronco e região proximal das extremidades. $^{2-3}$

- O eritema anular centrifugo consiste numa reação de hipersensibilidade cutânea, que se manifesta sob a forma de pápulas eritematosas que migram e aumentam perifericamente, adquirindo configuração policíclica com hipopigmentação central, que pode surgir em contexto infecioso, farmacológico, de doença sistémica e paraneoplásico. ${ }^{1-4,14}$

- O eritema crónico migrans, por sua vez, trata-se de uma lesão em alvo, que surge inicialmente como pequena mácula ou pápula, mas que vai aumentando lentamente, podendo associar-se a alterações articulares, cardíacas e neurológicas, como parte integrante da doença de Lyme, sendo a sua manifestação cutânea mais característica., ${ }^{1,-4,14}$

- A artrite idiopática juvenil caracteriza-se por um exantema macular e evanescente associado a artrite e febre. ${ }^{1}$

- Por último, o lúpus eritematoso cutâneo subagudo, um subtipo de lúpus eritematoso cutâneo, caracterizado clinicamente por lesões papuloescamosas e/ou policíclicas, que surgem em áreas expostas ao sol..-4,13 Concluindo, existe uma grande variedade de patologias que se manifestam com lesões anulares, algumas com atingimento cutâneo isolado e outras com atingimento sistémico, não sendo sempre clara a sua distinção numa fase inicial. Uma anamnese detalhada e exame físicos completos são essenciais no sentido de direcionar o diagnóstico diferencial. As lesões destas patologias podem inicialmente ser semelhantes, mas rapidamente evoluem e assumem características típicas que permitem a diferenciação entre as mesmas. Poderá ser útil, em casos dúbios ou mais exuberantes, a reavaliação do doente a curto prazo. 
No caso apresentado, o facto das lesões serem evanescentes, de se assemelharem a lesões em alvo, mas não possuírem um centro verdadeiramente equimótico/purpúrico, de se associarem a edema acral mas não a febre alta, atingimento das mucosas ou articular e de haver um trigger suspeito (infeção/antibiótico) possibilitou, desde a observação inicial, considerar que se estava perante um caso de urticária multiforme, não havendo por isso necessidade de investigação complementar ou cuidados mais específicos.

\section{REFERÊNCIAS BIBLIOGRÁFICAS}

1. Emer JJ, Bernardo SG, Kovalerchik O, Ahmad M. Urticaria multiforme. J Clin Aesthet Dermatol. 2013;6(3):34-9.

2. Narváez D, Di Martino-Ortiz B, Rodríguez-Masi M. Annular skin lesions in childhood: review of the main differential diagnoses. Our Dermatol Online. 2017;8(1):75-80.

3. Unwala R. Approach to the patient with annular skin lesions. UpToDate [Internet]; 2019 Dec 13 [updated May 2021]. Available from: https://www.uptodate.com/contents/approach-to-the-patient-withannular-skin-lesions

4. Shah KN, Honig PJ, Yan AC. Urticaria multiforme: a case series and review of acute annular urticarial hypersensitivity syndromes in children. Pediatrics. 2007;119(5):1177-83.

5. Pinho L, Oliveira S, Silva C. Urticária multiforme. Acta Pediatr Port. 2012:43(1):41-2.

6. Sánchez-Holgado M, Sánchez-Estella J. Urticaria multiforme, una entidad infradiagnosticada [Urticaria multiforme, a cutaneous disorder infradiagnosticated]. Rev Pediatr Aten Primaria. 2019;21(84):401-3. Spanish
7. Siedner-Weintraub Y, Gross I, David A, Reif S, Molho-Pessach V. Paediatric erythema multiforme: epidemiological, clinical and laboratory characteristics. Acta Derm Venereol. 2017;97(4):489-92.

8. Chan M, Goldman RD. Erythema multiforme in children: the steroid debate. Can Fam Physician. 2013;59(6):635-6.

9. Del Pozzo-Magaña BR, Lazo-Langner A. Serum sickness-like reaction in children: review of the literature. EMJ Dermatol. 2019;7(1):106-11.

10. Brewer JD, Davis MD. Urticarial vasculitis. UpToDate [Internet]; 2020 Mar 17 [updated 2021 May]. Available from: https://www.uptodate. com/contents/urticarial-vasculitis

11. Alhammadi AH, Adel A, Hendaus MA. Acute hemorrhagic edema of infancy: a worrisome presentation, but benign course. Clin Cosmet Investig Dermatol. 2013;6:197-9.

12. Pinto AP, Aguiar C, Dinis MJ, Ramos S. Edema agudo hemorrágico do lactente: a (re) conhecer. Nascer Crescer. 2016;25(4):251-4.

13. Salaeva K, Demir FT, Altunay IK, Yalçın O, Salman KE. Annular and polycyclic erythematous lesions in a child. J Cutan Med Surg. 2017;21(1): 60.

14. Saha A, Seth J, Pradhan S. Annular erythema in pediatric population. Indian J Paediatr Dermatol. 2016;17(3):167-72.

\section{CONFLITO DE INTERESSES}

Os autores declaram não possuir quaisquer conflitos de interesse.

\section{ENDEREÇO PARA CORRESPONDÊNCIA}

Diana Reis Monteiro

E-mail: diana.reis.monteiro@gmail.com

https://orcid.org/0000-0002-0827-8723

Recebido em 23-04-2020

Aceite para publicação em 16-12-2020 


\section{ABSTRACT}

\section{URTICARIA MULTIFORME: BASED ON A CASE REPORT}

Introduction: The rash in pediatric patients is often a challenge in daily clinical practice, as it can be associated with a wide variety of disorders, some with isolated cutaneous symptoms, others with systemic involvement, from benign and self-limited illnesses to more serious conditions that may require specific treatment. The authors report a case of urticaria multiforme with the aim of analyzing the semiological aspects of this pathology, its benign character, the differential diagnoses to be considered and the therapy to be instituted.

Case report: Eleven-month-old male infant, without major pathological history, was brought to the emergency department for an evanescent rash and peripheral edema with approximately 24 hours of evolution, without fever nor other associated complaints. He had finished amoxicillin with clavulanic acid due to acute otitis two days before being brought to the emergency department. On physical examination, a maculopapular rash stood out, with annular, polycyclic lesions, with an erythematous halo and a clear center, located on the face, trunk, and limbs, pruritic, associated with slight edema of the hands, feet, and face, without petechiae nor affecting the mucous membranes. No other relevant findings. Laboratory tests were not necessary, and the patient was discharged with a diagnosis of urticaria multiforme, with post-infectious/post-pharmacological association, treated with oral antihistamine and corticosteroids. Complete resolution of the lesions occurred approximately 48 hours later. Comment: Urticaria multiforme is a benign and self-limited disorder that appears mainly in pediatric age, characterized by the appearance of an erythematous maculopapular rash, with annular, polycyclic lesions, evanescent, easily mistaken with other more severe illnesses. Initially, it may be similar to erythema multiforme, serum sickness-like reaction, urticarial vasculitis, and acute hemorrhagic edema of infancy, however, these entities represent different pathologies, with different approaches and prognoses, therefore the clinical distinction between them is extremely important.

Keywords: Exanthema; Urticaria; Infant. 